\title{
Age-Related miRNA-Mediated Regulatory Networks Orchestrating Chronological Development of Meristems in Larix Kaempferi
}

\author{
Wan-Feng $\mathrm{Li}^{1} \cdot \mathrm{Li}-$ Wang $\mathrm{Qi}^{1} \cdot$ Wen-Hua Yang ${ }^{1}$
}

Received: 11 January 2021 / Accepted: 6 July 2021 / Published online: 22 July 2021

(c) The Author(s) 2021

\begin{abstract}
Plant growth and development is usually characterized by chronological age over the plants' lifetimes. Age-related changes actually originate with meristems because they control if, where, when, and how new tissues are formed along the axis of the shoot. The "time-keeping" of plant meristem development is a complex process. To uncover the post-transcriptional regulation underlying the chronological development of Larix kaempferi (Japanese larch) meristems, we investigated the miRNAmediated regulatory network in the defoliated, uppermost main stems of 1-, 2-, 5-, 10-, 25-, and 50-year-old L. kaempferi using RNA-seq methods. We identified 29 high-confidence miRNAs, three of which were defined, age-related miRNAs whose expression changed depending on L. kaempferi age, and 17 showed coordinated expression patterns with three agerelated miRNAs based on hierarchical correlations. All hierarchically coordinated miRNAs and their targets constituted a miRNA-mediated regulatory network. The developmental timing pathway lka-miR-1-5p-156-SBP/SPL (Squamosa Promoter Binding Protein-Like), the lignin biosynthesis pathway lka-miR-7,13-5p-397-LAC (Laccase), and an unknown pathway lkamiR-3-5p-CMSS1 (Cms1 Ribosomal Small Subunit Homolog) were age-driven, and information from auxin and light could be integrated by the lka-miR-9-5p-390-TAS/ARF (Trans-Acting siRNA3/Auxin Response Factor) and lka-miR-8-5p-IRL4 (Plant Intracellular Ras-Group-Related LRR Protein 4) pathways, respectively. Age-driven regulatory network will lead the way to understand which and how genes mutually cross-regulate their activity orchestrating development of meristems of $L$. kaempferi with age. We also discussed and contributed to miRNA annotation and nomenclature.
\end{abstract}

Keywords Age $\cdot$ Larix kaempferi $\cdot$ miRNA $\cdot$ Meristem development $\cdot$ Regulatory network

\section{Introduction}

Plant growth and development is usually characterized by chronological age at various scales over the plants' lifetimes (Gatsuk et al. 1980). Age-related changes actually originate with meristems because they control if, where, when, and how new tissues are formed along the axis of the shoot (Poethig 1990). Pioneering studies of vegetative phase change and floral transition, as well as root development, have demonstrated that meristems will change position, identity, and

Handling Editor: Nicola busatto.

Wen-Hua Yang

yangwh@caf.ac.cn

1 State Key Laboratory of Tree Genetics and Breeding, Key Laboratory of Tree Breeding and Cultivation, National Forestry and Grassland Administration, Research Institute of Forestry, Chinese Academy of Forestry, Beijing, China activity to match the dynamic growth and development of plants at different life stages (Greenwood 1995; Telfer et al. 1997; Willmann and Poethig 2005; Zotz et al. 2011; Zhao et al. 2015; Xu et al. 2016; Gorham et al. 2018).

Meristem activity is a highly dynamic process which must be coordinately controlled by both extrinsic and intrinsic regulatory networks responding to environmental and organismal cues, such as temperature, light, hormones, carbohydrates, and age (Poethig 1990, 2013; Adrian et al. 2009; Amasino 2010; Srikanth and Schmid 2011; Huijser and Schmid 2011; Nieminen et al. 2015; Ye and Zhong 2015). Several pathways governing meristems have been postulated in Arabidopsis thaliana. For example, WUSCLV and miR156-SPL pathways play critical roles in the control of shoot apical meristem (SAM) (Lenhard and Laux 1999; Schoof et al. 2000; Fouracre and Poethig 2019). At the genetic level, thousands of genes which constitute a complex molecular regulatory network are involved in meristematic activity (Mouradov et al. 2002; Teotia and Tang 
2015; Brunoni et al. 2019). As regulatory network connectivity increases, it has become quite clear that the crosstalk among some meristem-associated pathways can integrate information from light, temperature, hormones, and age to ensure the rhythmic growth (Pajoro et al. 2014; Nieminen et al. 2015; Bustamante et al. 2016).

MiRNAs are key players in controlling the establishment, patterning, and function of meristems. For example, miR165/6-mediated post-transcriptional regulation of homeodomain-leucine zipper transcription factors orchestrate shoot and root development (Muraro et al. 2014; Couzigou and Combier 2016), vascular differentiation, and patterning (Byrne 2006; Carlsbecker et al. 2010; Miyashima et al. 2011; Zhu and Helliwell 2011; Jouannet et al. 2015; Nieminen et al. 2015; Ramachandran et al. 2016). The differentiation of vascular tissue is closely associated with wood formation and properties (Côté et al. 2010). In addition, the miR156$S P L$ module controls vegetative phase change and floral transition (Wu and Poethig 2006; Wu et al. 2009), postgerminative change, tillering and branching (Chuck et al. 2007; Riese et al. 2007; Miura et al. 2010), plastochrons (Schwarz et al. 2008; Wang et al. 2008), root development (Aung et al. 2015; Yu et al. 2015; Hobecker et al. 2017), and shoot regenerative capacity (Zhang et al. 2015). A third small RNA, miR390, regulates the auxin responsive factors $A R F 2, A R F 3$, and ARF4 by controlling TAS3-derived transacting short interfering RNAs (tasiRNAs). The miR390/ tasiRNA/ARF regulatory module influences the timing of leaf development (Fahlgren et al. 2006; Hunter et al. 2006), organ polarity (Garcia et al. 2006), and lateral root and gall development in A. thaliana (Marin et al. 2010; Cabrera et al. 2016; Hobecker et al. 2017). Taken together, numerous miRNAs are involved in meristem activities and direct various developmental processes (Poethig 2009; Teotia and Tang 2015; Hobecker et al. 2017).

So far most of knowledge on the molecular mechanisms of meristem activity is obtained from studies on model plants such as annual and herbaceous plant A. thaliana, which cannot fully explain the complex regulatory networks orchestrating the meristem activity of perennial woody plants. In particular, gymnosperms often follow different developmental and physiological rules from angiosperms (Johnson et al. 2012), suggesting that the molecular mechanism of meristem activity might also be different from that of angiosperms. Larix kaempferi is typical for gymnosperms and noted for its wood properties and wide adaptation (Lai et al. 2014). In the present study, we explored the miRNAmediated regulatory networks orchestrating the chronological development of its meristems by identifying coordinated miRNAs and their targets from L. kaempferi. This genomewide analysis provides clues for further molecular research on phase change, cambial activity/dormancy, and wood formation.

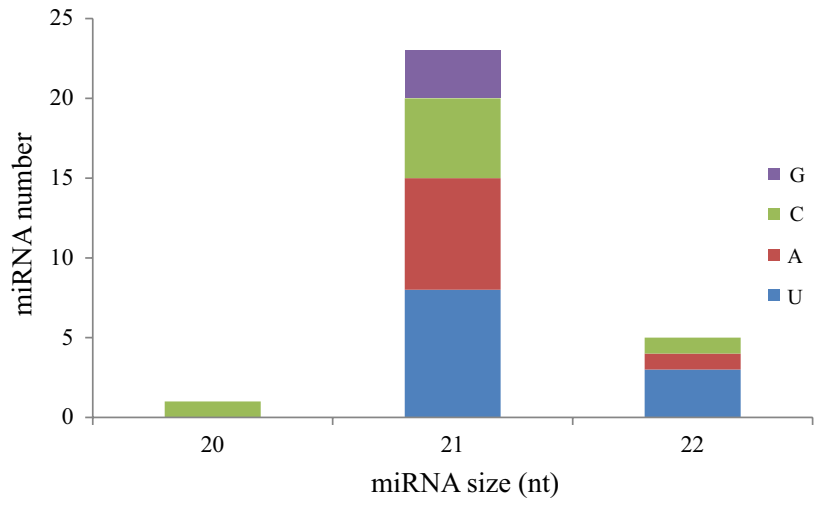

Fig. 1 Length distributions and percentages of 5'-terminal nucleotide of Larix kaempferi miRNAs

\section{Results}

\section{Identification and Characterization of miRNAs from the Stems of $L$. kaempferi with Different Ages}

To identify with high-confidence miRNAs within the complex sRNAome, 5,945,922 unique sRNA sequences were aligned to the L. kaempferi transcriptome database (Li et al. 2017), and the read patterns that were predicted using the MIREAP algorithm were checked manually. Only those sequences that met the criteria described by Kozomara et al. (2019) and Axtell and Meyers (2018) were considered as high-confidence miRNAs. As a result, a total of 15 hairpin loci were identified and then 29 L. kaempferi miRNAs were generated from the 15 hairpin precursors because the same mature miRNAs were produced from the 5' arms of both the 7th and 13th precursors (Table 1). The hairpin structures were predicted by MFOLD (Supplementary Fig. S1) and the mature miRNAs are shown in Table 1. Since both arms of a precursor are productive (Marco et al. 2012), we named the mature miRNAs using our recommended nomenclature and analyzed them as unique miRNA.

Throughout our work, we modified the miRNA nomenclature recommended by Griffiths-Jones et al. (2006) and Kozomara and Griffiths-Jones (2013). We adopted the forms lka-miR-n-5p and lka-miR-n-3p for miRNA names. The letter " $n$ " in these miRNA identifiers is a natural number and designates distinct hairpin loci that give rise to successive miRNAs. If a mature miRNA was derived from multiple precursors, it was necessary to list the number, separated by commas, to designate specific hairpin loci in numerical order. For example, lka-miR-7,13-5p-397 was assigned to $1 \mathrm{ka}-\mathrm{miR}-7-5 \mathrm{p}$ and $1 \mathrm{ka}-\mathrm{miR}-13-5 \mathrm{p}$, which were respectively derived from the 7 th and 13 th precursors with the same mature miRNA sequences. The numbered 
Table 1 miRNAs identified in current-year uppermost stems from Larix kaempferi at different ages

\begin{tabular}{|c|c|c|c|c|c|c|}
\hline Precursor name & $\mathrm{LP}(\mathrm{nt})$ & MFE (kcal/mol) & miRNA name & miRNA sequences $\left(5^{\prime}-3^{\prime}\right)$ & $\begin{array}{l}\text { miRNA } \\
\text { length (nt) }\end{array}$ & miRNA family \\
\hline lka-miR-1 & 100 & -51.97 & $\begin{array}{l}\text { lka-miR-1-3p } \\
\text { lka-miR-1-5p-156 }\end{array}$ & $\begin{array}{l}\text { GTGAGCTCTCTCTTTGTCACC } \\
\text { TGACAAAGAGAGAGAGCACGC }\end{array}$ & $\begin{array}{l}21 \\
21\end{array}$ & $\begin{array}{l}\text { Novel } \\
\text { miR156 }\end{array}$ \\
\hline lka-miR-2 & 79 & -24.56 & $\begin{array}{l}\text { lka-miR-2-3p } \\
\text { lka-miR-2-5p }\end{array}$ & $\begin{array}{l}\text { CTGGTGGAGAGTCCGGTGTCA } \\
\text { TTGTGACGCGGTACTCCCACA }\end{array}$ & $\begin{array}{l}21 \\
21\end{array}$ & $\begin{array}{l}\text { Novel } \\
\text { Novel }\end{array}$ \\
\hline lka-miR-3 & 90 & -41.58 & $\begin{array}{l}\text { lka-miR-3-3p-162 } \\
\text { lka-miR-3-5p }\end{array}$ & $\begin{array}{l}\text { TCGATAAACCTCTGCATCCAG } \\
\text { GGATGCAAAGGGTTTACCGACC }\end{array}$ & $\begin{array}{l}21 \\
22\end{array}$ & $\begin{array}{l}\operatorname{miR} 162 \\
\text { Novel }\end{array}$ \\
\hline lka-miR-4 & 78 & -41.59 & $\begin{array}{l}\text { lka-miR-4-3p } \\
\text { lka-miR-4-5p }\end{array}$ & $\begin{array}{l}\text { TCAGAGTTTTGCCGGTTCCACC } \\
\text { CGGACTGGCATAACTCTGACC }\end{array}$ & $\begin{array}{l}22 \\
21\end{array}$ & $\begin{array}{l}\text { Novel } \\
\text { Novel }\end{array}$ \\
\hline lka-miR-5 & 89 & -36.03 & $\begin{array}{l}\text { lka-miR-5-3p-11425 } \\
\text { lka-miR-5-5p }\end{array}$ & $\begin{array}{l}\text { TTTTACTGCTATATCTTTTCC } \\
\text { AGAAGGAAAAGATATAGCAGT }\end{array}$ & $\begin{array}{l}21 \\
21\end{array}$ & $\begin{array}{l}\operatorname{miR} 11425 \\
\text { Novel }\end{array}$ \\
\hline lka-miR-6 & 96 & -50.12 & $\begin{array}{l}\text { lka-miR-6-3p } \\
\text { lka-miR-6-5p }\end{array}$ & $\begin{array}{l}\text { ATGAACTGGCGTGGTTGAGCT } \\
\text { CTCAACCACGCCAGTTCATTC }\end{array}$ & $\begin{array}{l}21 \\
21\end{array}$ & $\begin{array}{l}\text { Novel } \\
\text { Novel }\end{array}$ \\
\hline lka-miR-7 & 95 & -31.51 & $\begin{array}{l}\text { lka-miR-7-3p } \\
\text { lka-miR-7-5p-397 }\end{array}$ & $\begin{array}{l}\text { ATGCTGTACACAATGATAAGC } \\
\text { TCATCATTGAGAGCAGCATTG }\end{array}$ & $\begin{array}{l}21 \\
21\end{array}$ & $\begin{array}{l}\text { Novel } \\
\text { miR397 }\end{array}$ \\
\hline lka-miR-8 & 90 & -38.92 & $\begin{array}{l}\text { lka-miR-8-3p } \\
\text { lka-miR-8-5p }\end{array}$ & $\begin{array}{l}\text { TACAGCTATATCTTTTCCATC } \\
\text { AAAAGATATAGCGGTAAGAGT }\end{array}$ & $\begin{array}{l}21 \\
21\end{array}$ & $\begin{array}{l}\text { Novel } \\
\text { Novel }\end{array}$ \\
\hline lka-miR-9 & 91 & -50.97 & $\begin{array}{l}\text { lka-miR-9-3p } \\
\text { lka-miR-9-5p-390 }\end{array}$ & $\begin{array}{l}\text { CGCTATCCATCCTGGGCTTCA } \\
\text { AAGCTCAGGAGGGATAGCGCC }\end{array}$ & $\begin{array}{l}21 \\
21\end{array}$ & $\begin{array}{l}\text { Novel } \\
\text { miR390 }\end{array}$ \\
\hline lka-miR-10 & 96 & -49.08 & $\begin{array}{l}\text { lka-miR-10-3p-166 } \\
\text { lka-miR-10-5p }\end{array}$ & $\begin{array}{l}\text { TCGGACCAGGCTTCATTCCCC } \\
\text { GGAATGTTGTCTGGCTCGACT }\end{array}$ & $\begin{array}{l}21 \\
21\end{array}$ & $\begin{array}{l}\operatorname{miR} 166 \\
\text { Novel }\end{array}$ \\
\hline lka-miR-11 & 76 & -46.52 & $\begin{array}{l}\text { lka-miR-11-3p } \\
\text { lka-miR-11-5p }\end{array}$ & $\begin{array}{l}\text { CATACGGTACGATCGACGTC } \\
\text { CCGTCGGTCGTACTGTATGGT }\end{array}$ & $\begin{array}{l}20 \\
21\end{array}$ & $\begin{array}{l}\text { Novel } \\
\text { Novel }\end{array}$ \\
\hline lka-miR-12 & 76 & -58.78 & $\begin{array}{l}\text { lka-miR-12-3p } \\
\text { lka-miR-12-5p }\end{array}$ & $\begin{array}{l}\text { TTCAAAGCAGCATCTCGTTTCT } \\
\text { AAAGAGATGCTGCTTTGAATG }\end{array}$ & $\begin{array}{l}22 \\
21\end{array}$ & $\begin{array}{l}\text { Novel } \\
\text { Novel }\end{array}$ \\
\hline lka-miR-13 & 95 & -39.95 & $\begin{array}{l}\text { lka-miR-13-3p } \\
\text { lka-miR-13-5p-397 }\end{array}$ & $\begin{array}{l}\text { ATGCTGCATTCAACGATAAGC } \\
\text { TCATCATTGAGAGCAGCATTG }\end{array}$ & $\begin{array}{l}21 \\
21\end{array}$ & $\begin{array}{l}\text { Novel } \\
\text { miR397 }\end{array}$ \\
\hline lka-miR-14 & 81 & -30.53 & $\begin{array}{l}\text { lka-miR-14-3p } \\
\text { lka-miR-14-5p-482 }\end{array}$ & $\begin{array}{l}\text { AGTGGGAGCATAGGATAAGGCT } \\
\text { TCTTTCCTACTCСТCCCATTCC }\end{array}$ & $\begin{array}{l}22 \\
22\end{array}$ & $\begin{array}{l}\text { Novel } \\
\text { miR482 }\end{array}$ \\
\hline lka-miR-15 & 90 & -45.6 & $\begin{array}{l}\text { lka-miR-15-3p-396 } \\
\text { lka-miR-15-5p-396 }\end{array}$ & $\begin{array}{l}\text { GCTCAAGAAAGCTGTGGGAAA } \\
\text { TTCCACAGCTTTCTTGAACTA }\end{array}$ & $\begin{array}{l}21 \\
21\end{array}$ & $\begin{array}{l}\operatorname{miR} 396 \\
\operatorname{miR} 396\end{array}$ \\
\hline
\end{tabular}

$L P$ length of precursor; $M F E$ minimal folding energy

suffixes were assigned the same number as their homologous miRNAs to show mutual homology. After annotation, we obtained nine conserved and twenty novel miRNAs (Table 1).

The lengths of all annotated miRNA varied from 20 to $22 \mathrm{nt}$, and 21-nt miRNAs predominated (82.76\%), followed by 22 -nt (17.24\%). The tendency of 5'-terminal nucleotides of all annotated miRNAs was analyzed, and uridine predominated, a total of 11 miRNAs (37.93\%) started with a 5'-uridine (Fig. 1).

\section{Age-Related Changes of miRNA Expression}

Expression levels of the miRNAs were determined using normalized transcripts (Supplementary Table S1). To explore the essential relationships between age and miRNA expression levels, regression analysis was performed using linear-to-cubic models for each miRNA with base-2, logtransformed age as predictor, and its expression level as response (Supplementary Table S2). The results of regression analysis showed that cubic polynomial repression models can easily explain the changes of three miRNAs' expressions with age: lka-miR-1-5p-156, lka-miR-3-5p, and lka-miR-7,13-5p-397 (Table 2). The functions for describing the relationship between miRNA expression and age were $Y$ $=-0.466 x^{3}+5.094 x^{2}-17.276 x+22.022, Y=0.196 x^{3}-0$ $.804 x^{2}-1.994 x+20.160$, and $Y=-0.012 x^{3}+0.119 x^{2}-0$. $305 x+0.207$ for lka-miR-1-5p-156; lka-miR-3-5p; and lkamiR-7,13-5p-397, respectively (Table 2). Therefore, these three miRNAs were defined age-related miRNAs.

Interestingly, these three miRNAs were expressed strongly in the 1-year-old trees, although the patterns were 
Table 2 Regression models for three age-related miRNAs in Larix kaempferi

\begin{tabular}{lllllll}
\hline MiRNA Name & Regression model & $R$ & $R$ square & $\begin{array}{l}\text { Adjusted } R \\
\text { square }\end{array}$ & $F$ & Sig \\
\hline lka-miR-1-5p-156 & Cubic & 0.98 & 0.97 & 0.91 & 18.66 & 0.05 \\
lka-miR-3-5p & Cubic & 0.99 & 0.99 & 0.96 & 45.81 & 0.02 \\
lka-miR-7,13-5p-397 & Cubic & 0.99 & 0.98 & 0.94 & 27.55 & 0.04 \\
\hline
\end{tabular}

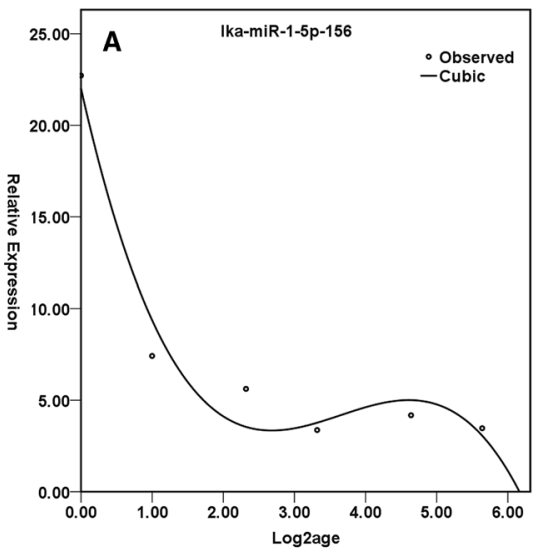

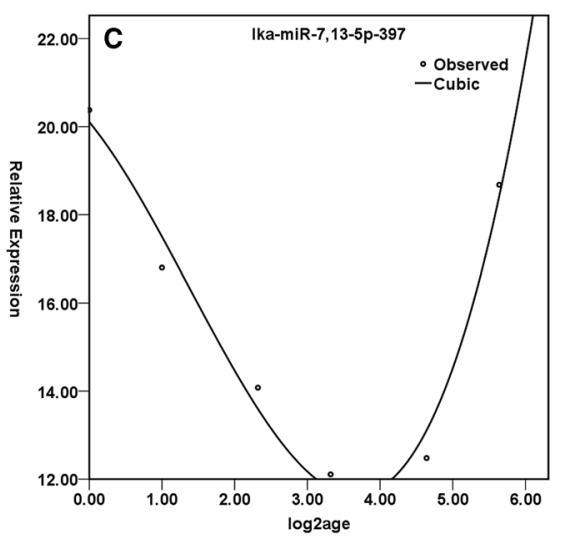

Fig. 2 Expression changes of three age-related miRNAs with age

different. Lka-miR-1-5p-156 was strongly expressed in the 1-year-old trees and then its level declined (Fig. 2a). The level of lka-miR-3-5p became undetectable in the 2-yearold and 5-year-old trees, and then its expression increased gradually, reaching a peak in the 25-year-old tree (Fig. 2b). Lka-miR-7,13-5p-397 were expressed strongly in the 1- and 50-year-old trees (Fig. 2c).

\section{Statistical Evidence of Coordinated miRNAs}

Based on hierarchical correlations of expression patterns of miRNAs, a total of 17 miRNAs appeared to be coordinated with three age-related miRNAs. Expression pattern of one miRNA was often correlated with those of several others either positively or negatively. Many miRNA expressions changed together in the same direction, yielding positive correlations; whereas a few of miRNA expressions moved in opposite directions representing negative correlations. For instance, expression pattern of lka-miR-1-5p-156 was positively correlated with that of 1ka-miR-1-3p, 1ka-miR-5-3p-11425, lka-miR-14-3p, and lka-miR-14-5p-482, but it was inversely correlated with that of lka-miR-8-5p (Fig. 3). Negative correlations between expression patterns of miRNAs were also observed, including lka-miR-3-3p-162 vs. 1ka-miR-6-5p and lka-miR-15-3p-396 and lka-miR-15-3p-396 vs. lkamiR-10-3p-166 and lka-miR-12-5p (Fig. 3). Furthermore, several miRNAs, such as lka-miR-1-3p, lka-miR-9-5p-390, lka-miR-14-3p, and lka-miR-14-5p-482, appeared associated with seven or more miRNAs, denoting their association with multiple miRNA pathways as hubs (Fig. 3).

\section{MiRNA390-TAS3-ARF Pathway in L. kaempferi}

We identified one TAS3 transcript containing two miR390 complementary sites in the L. kaempferi transcriptome, in which the 5' site was mismatched at the 10th position, while the 3' site had a perfect match at the corresponding position (Fig. 4). According to the two-hit model (Allen et al. 2005), 17 tasiRNA pairs were precisely phased from the 357-nucleotide region between two argonaute 7 cleavage sites in 21-nucleotide intervals. The phased positions were coded as described by Allen et al. (2005), with mature tasiRNAs named with the 'tasiR' prefix, followed by their successive directions and positions [e.g., tasiR5'D1(+), 5'D2(+), and so on or, on the opposite strand, 5'D1(-), 5'D2(-), and so on]. Three tasiRNAs [tasiR5'D10(+), tasiR5'D11(+), and tasiR5'D11(-)] derived from TAS3 were predicted, using miRNA/mRNA interaction rules, to target L. kaempferi ARF transcripts. Both tasiR5'D10(+) and tasiR5'D11(+) target the same $A R F 2$ and ARF4 transcript sites because of their highly similar sequences (Supplementary Table S3). 


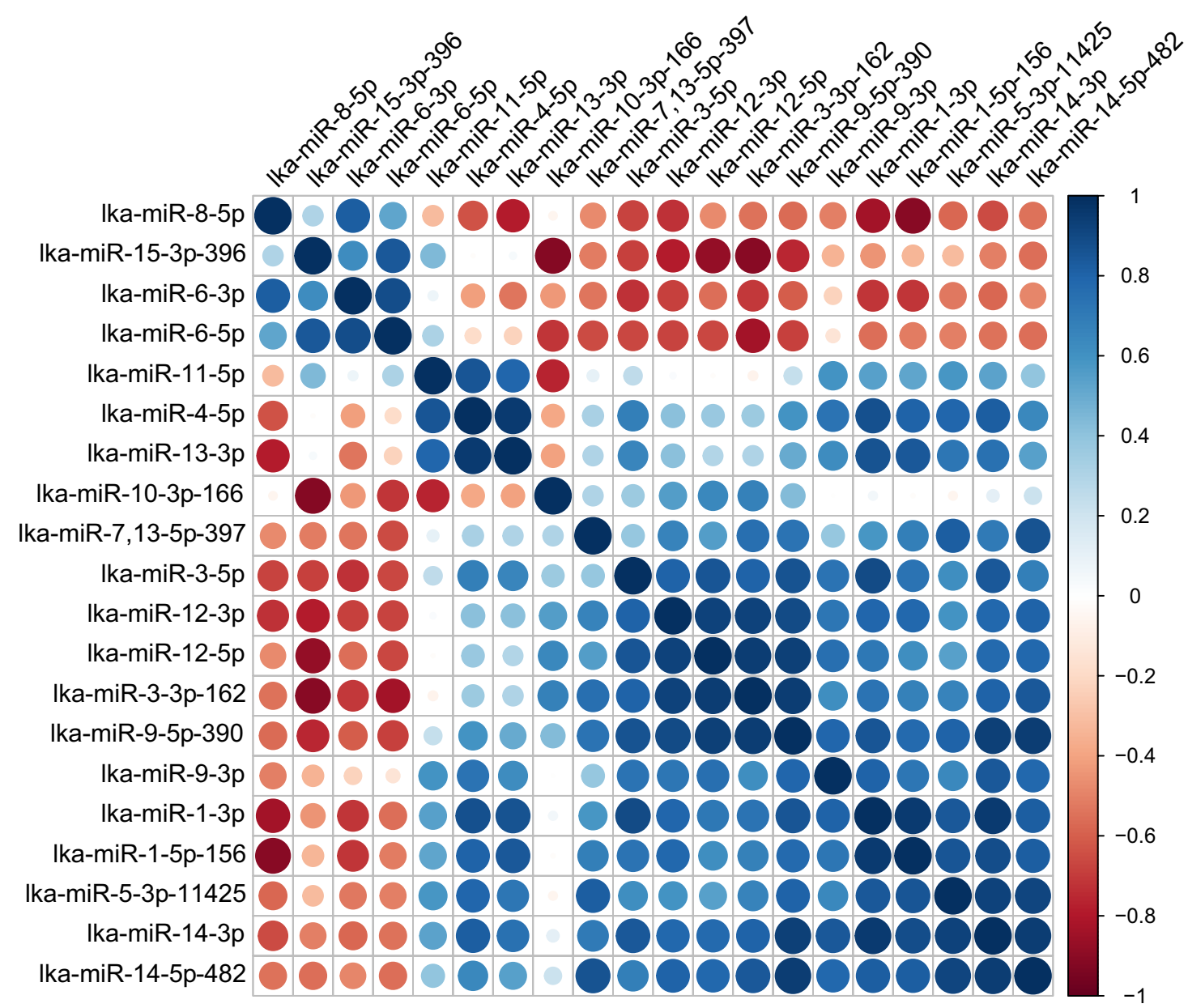

Fig. 3 Correlations between expression patterns of coordinated miRNAs

\section{Target Genes of L. kaempferi miRNAs}

Since individual miRNA works by targeting mRNAs, blocking translation, or causing mRNA degradation, identification of miRNA target genes is crucial for understanding the function of miRNA. We predicted the target genes of all 29 miRNAs using a computerized approach. A total of 73 transcripts were identified as putative target genes, of which 42 were annotated and named after homologous sequences in UniProtKB (Supplementary Table S4). According to GO (www.geneontology.org) annotations, they covered a broad range of molecular functions in many biological processes (Supplementary Table S5).

\section{MiRNA-Mediated Regulatory Network}

The hierarchical correlations between the expression patterns of miRNAs and the interaction of miRNAs and their targets constituted a regulatory network to orchestrate L. kaempferi meristem development chronologically. This miRNA-mediated regulatory network consists of multiple interconnected
miRNA pathways. Both the lka-miR156-SPL and the lka-miR9-5p-390-TAS3-ARF pathways were interconnected by lkamiR-1-3p-unkown and lka-miR-14-5p-482-unkown pathways (Fig. 5). Lka-miR-7,13-5p-LAC pathway was also connected with lka-miR-14-5p-482-unknown pathway (Fig. 5). The lkamiR-8-5p-IRL4 pathway is associated with lka-miR156-SPL pathway via strong negative correlation between expression patterns of miRNAs (Fig. 5).

Although we were unable to find out and annotate the targets of many of our miRNAs, the functions of the annotated targets demonstrated that multiple biological processes were involved in the chronological development of meristems in $L$. kaempferi, including cone development, lignin biosynthetic and catabolic processes, RNA processing and modification, protein phosphorylation, and signal transduction (Fig. 5; Supplementary Table S5). 


\section{LkTAS3}

5'D17(+)

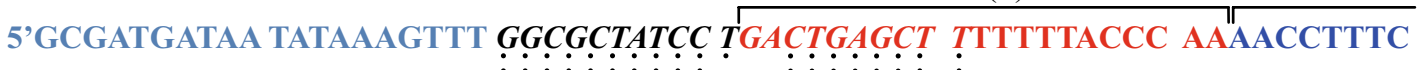

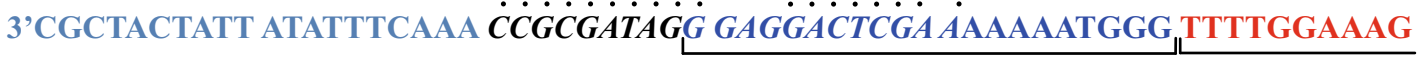
5’D17(-)

\begin{tabular}{l}
$\frac{5{ }^{\prime} \mathrm{D} 16(+)}{\text { + AACCCTCTCC CAAACCCATA TCATTCACTC ATGCAAATAT TGGATCTGAAATCGCCATCT }}$ \\
- TTGGGAGAGG GTTTGGGTAT AGTAAGTGAG TACGTTTATA ACCTAGACTT TAGCGGTAGA \\
\hline 5'D16(-) 5'D15(-)
\end{tabular}

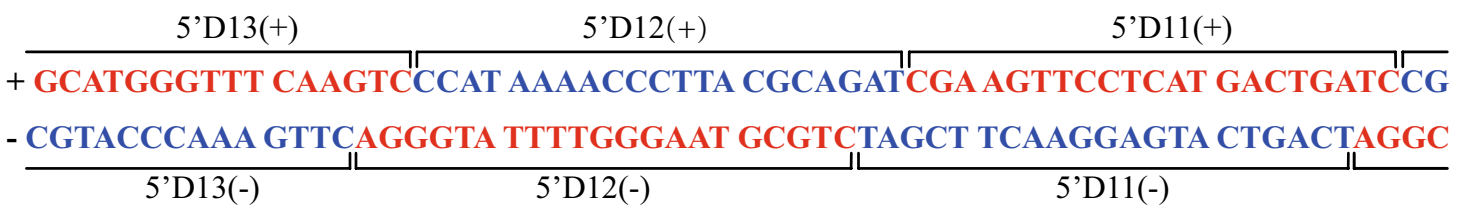

$\frac{\text { 5'D10 }(+)}{\text { + TAGCCTTGTG TTCGTTTGCC ATCACCCCCA AACTAAGCCT' TTCTTGACCT TGTAAGACCT }}$
$\frac{\text { - ATCGGAACAC AAGCAAACGG TAGTGGGGGT TTGATTCGGA AAGAACTGGA ACATTCTGGA }}{\text { 5'D10(-) 5’ }}$

+ TTTCTTGACC TTGTAAGACC AGCCATCGAA TCCTGAGAAC AGCGGCACAT TTCGACTCCT
- AAAGAACTGG AACATTCTGG TCGGTAGCTT AGGACTCTTG TCGCCGTGTAAAGCTGAGGA 5’D7(-) 5'D6(-) 5'D5(-)

\begin{tabular}{l} 
+ CGCCCAATTC TACTATAAGT TACTGGCCAT AGGACTGGCA ATGAGGTCGC TCAACTCTCA \\
- GCGGGTTAAG ATGATATTCA ATGACCGGTA TCCTGACCGT TACTCCAGCG AGTTGAGAGT \\
\hline 5'D4(-) 5'D3(+)
\end{tabular}

$5^{\prime} \mathrm{D} 1(+)$

+ AАСААТСТTC ТTCTAACTAG TCTATCCCTC CTGAGCTATT ACAGTTGAGT TTCAAGTTCT 3 , - TTGTTAGAAG AAGATTGCCG $\dot{C} \dot{G} \dot{A} \dot{T} \dot{A} \dot{G} \dot{G} \dot{G} \dot{A} \dot{G} \dot{G} \ddot{A} \ddot{C} \dot{C} \dot{G} \dot{A} A A A$ TGTCAACTCA AAGTTCAAGA 5 , 5'D1(-)

Fig. 4 LkTAS3 EST contained dual miR390 complementary sites. Seventeen tasiRNA pairs are predicted between two miR390 cleavage sites in 21-nucleotide intervals and coded as 5'D1(+), 5'D2(+), and so on, or 5'D1(-), 5'D2(-), and so on, on the opposite strand. Two miR390 complementary sites are highlighted by italic fonts 


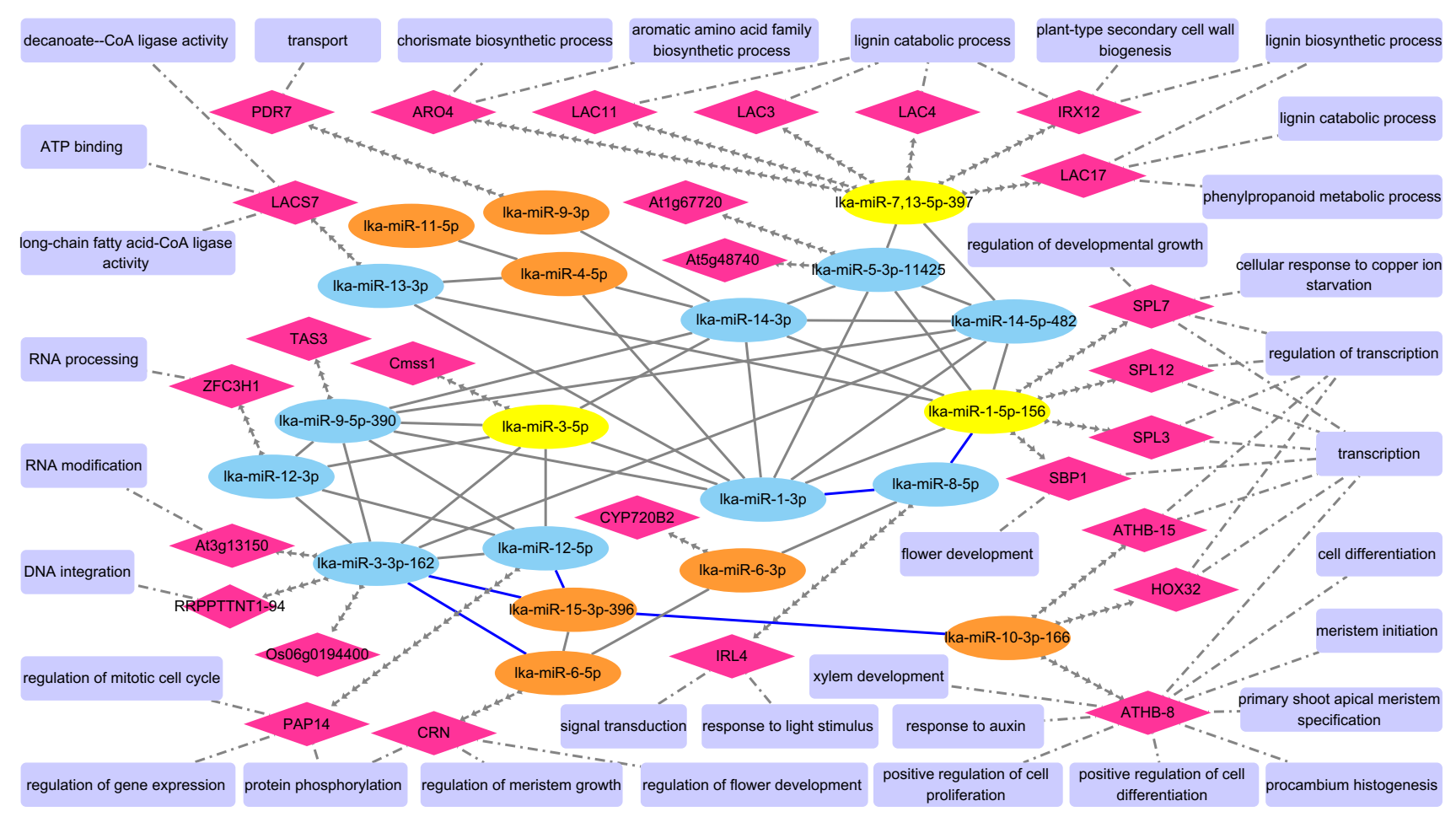

Fig. 5 miRNA-mediated regulatory network underlying chronological development of meristems of Larix kaempferi. Ellipse nodes correspond to the miRNAs, diamond nodes are the target genes, and rectangle-rounded corners nodes represent GO-biological processes of miRNA targets. Age-related miRNAs are marked in yellow, miRNAs directly correlated with age-related miRNAs are marked in pale

\section{Discussion}

\section{Annotation of miRNAs Based on Deep Sequencing Data}

To thoroughly investigate the biogenesis, function, and evolution of miRNA in the complex context of inconstant RNA populations, miRNA annotation is critical. Revised criteria for plant miRNA annotation that minimizes false positives have been proposed (Axtell and Meyers 2018; Kozomara et al. 2019), and there are slight differences in the keynotes of the two criteria. Kozomara et al. (2019) highlighted the importance of the pattern of reads mapped to a hairpin locus for discriminating robustly bona fide miRNA from other transcribed fragments. Axtell and Meyers (2018) emphasized replication, contending that homology-based annotations should be treated as miRNA only when all criteria are presented by sRNA-seq. Actually, both criteria should be addressed when high-confidence miRNAs are identified from high-throughput sRNA datasets.

In the present study, only the sequences that met both proposed criteria were considered as high-confidence canonical miRNAs. Homology-based inference was used for homology cyan, and miRNAs indirectly correlated with age-related miRNAs are marked in orange. Solid lines represent miRNA pairs, of which negative correlations are marked in blue, whereas positive correlations are marked in black. Separate arrows represent miRNA-mRNA pairs and marquee dash dot represents mRNA-annotation pairs

detection to supplement annotation, so if sequence homology existed between putative miRNA and a known miRNA, and their targets also showed significantly higher levels of sequence homology between each other, we considered them homologous. Our pioneering efforts in identifying miRNA from high-throughput sRNA datasets provide an efficient way to reduce the number of bad miRNA sequences.

\section{miRNA Nomenclature}

Although the miRNA nomenclature as recommended by miRBase (Griffiths-Jones et al. 2006; Kozomara and Griffiths-Jones 2010) has been widely accepted and used, the criteria for naming miRNA should be redefined over time due to ongoing refinement in the understanding of its origins, biosynthesis, and sequence variabilities as proposed by some leading scientists (Desvignes et al. 2015; Budak et al. 2016). Herein, we attempted to give some nomenclature guidelines in Larix to discriminate the same mature miRNAs derived from different precursors or different mature miRNAs produced from the same precursor, thus providing a better understanding of the context. 
As critical signs of communication, the names of miRNAs should at least incorporate their origins to avoid being confused with one another. The form of miRNA gene names (e.g., dme-miR-100/100* or dme-miR-100-5p/3p) currently in use sequentially assigns the number 100 to refer to the homologous relationships of miRNA gene loci in different species (Kozomara and Griffiths-Jones 2010, 2013). However, since different functional miRNAs produced by the same precursor may occur in different tissues at different developmental times or in different species, homology annotation is no longer suitable (Griffiths-Jones et al. 2011). Also, assigning the same number to miRNAs arising from the same precursor is not advisable because sequences derived from the opposite arms of the hairpin precursor often function differently and belong to different families.

Given that the hairpin precursor is a pivotal bridge connecting mature miRNAs and their gene loci, if a miRNA name contains the information of its precursor to denote its origin and numbered suffixes to show its homology, we would be free from interference of the same miRNAs derived from different precursors and different miRNAs produced from the same precursor. This system better enables comparative analyses of different tissues, developmental times, and evolutionary processes across species.

Therefore, names for miRNAs derived from the $5^{\prime}$, and $3^{\prime}$ arms of the precursor would take the form lka-miR-n-5p and lka-miR-n-3p, respectively, where $n$ designates distinct hairpin loci that give rise to mature miRNAs, while sequentially chronicling its identity, and $5 p$ and $3 p$ indicate the original arms of the precursors. If mature miRNA is derived from multiple precursors, then their numbers, separated by commas, designate specific hairpin loci in numerical order. For example, lka-miR-7,13-5p-397 is assigned to lka-miR-7-5p and $1 \mathrm{ka}-\mathrm{miR}-13-5 \mathrm{p}$, which were respectively derived from the 7th and 13th precursors with the same mature sequences. Complementary numbered suffixes are assigned numbers matching their homologous miRNAs to show homology to each other. In the future, if a specific hairpin locus owns its code when there is sufficient genetic information, the " $n$ " in the middle of its miRNA identifier may be easily replaced by the hairpin locus code.

\section{miRNA Regulation of Meristem Identity During $L$. kaempferi Tree Aging}

Meristems can fine-tune themselves to match dynamic growth and development, accompanied by age-related changes at various scales, throughout their life stages. This process is strictly controlled by a complex genetic network in which each component works in concert with the others. For example, both the miR156-SPL and the miR172-AP2 pathways antagonistically control the transition from juvenile to adult stage (Wu et al. 2009; Huijser and Schmid 2011;
Yamaguchi and Abe 2012; Tripathi et al. 2018). Moreover, miR172 targets AP2-like proteins, directly repressing ARF3 expression, which in turn diminishes $S P L 3$ levels (RubioSomoza and Weigel 2011). ARF2, ARF3, and ARF4 transcription factors are regulated by tasiRNAs from TAS3, and miR390 targets TAS3 to trigger the production of tasiRNAs (Allen et al. 2005). Herein, miRNA-mediated regulatory network showed that both lka-miR156-SPL and lka-miR-9-5p390-TAS3-ARF pathways were interconnected by lka-miR1-3p and lka-miR-14-5p-482 (Fig. 4), suggesting that they drive L. kaempferi meristem development in concert. Furthermore, the lka-miR-1-156 expression was nearly downregulated with age, showing a pattern consistent with those of A. thaliana, maize, and several woody species, including Acacia confusa, Acacia colei, Eucalyptus globulus, Hedera helix, and Quercus acutissima (Lauter et al. 2005; Wu and Poethig 2006; Wu et al. 2009; Huijser and Schmid 2011; Wang et al. 2011; Tripathi et al. 2018). Actually, it can scarcely be a coincidence that L. kaempferi miR156-SPL features match perfectly with those in these species, suggesting that miR156-SPL defines a conserved molecular connection between the development of meristem and its age.

Based on current understanding of molecular functions in meristems, miR156-SPL and miR172-AP2 cooperate in developmental timing. However, miR172 family members were not identified in our study. It was likely due to the limited number of transcripts. In addition, the current miRBase Release 22 (http://www.mirbase.org) does not contain any miR172 from gymnosperms, even though miR172 has been identified in some conifers (Zhang et al. 2012; Qiu et al. 2015). Therefore, it is still unknown whether the APETALA 2-like genes are progressively downregulated with age by miR172 in Larix or even in other gymnosperms.

\section{miRNA Regulation of Vascular Cambium During $L$. kaempferi Tree Aging}

Laccases are basically involved in lignin biosynthesis that is closely associated with the formation of the secondary cell wall of tracheary elements, sclereids, and many fiber types in vascular plants (Freudenberg 1959; Bao et al. 1993; Zhao et al. 2013, 2015; Lu et al. 2013; Yi Chou et al. 2018). To our knowledge, LAC4, LAC11, and LAC17 are involved in monolignol polymerization and lignification of vascular bundles and interfascicular fibers in A. thaliana stems (Berthet et al. 2011; Yi Chou et al. 2018). IRX12, encoding a laccase, is associated with secondary thickening of cell wall (Yang et al. 2007). The miR397-LAC pathway regulates lignin content and, consequently, affects the secondary cell wall of vessel elements, fibers, and sclereids (Berthet et al. 2011; Lu et al. 2013; Wang et al. 2014). Our results showed that age-related lka-miR-7,13-5p-397 mainly targeted laccase genes in Larix, indicating that the lka-miR-7,13-5p-397-LAC pathway may 
regulate the secondary cell wall formation of tracheids in the xylem and sclereids in the bark during L. kaempferi tree aging, and these data provide further information about the effects of age on wood formation ( $\mathrm{Li}$ et al 2017).

miR165/166-HD-ZIP III regulon is highly conserved and often interacts with other factors to control a broad range of developmental processes, such as apical development, inflorescence architecture, vascular specification, patterning, and differentiation (Turchi et al. 2015; Ramachandran et al. 2016; Alvarez Buylla et al. 2019). For example, ATHB8 contributes to the preprocambial cells against auxin perturbations to promote xylem formation (Baima et al. 2001; Donner et al. 2009; Smetana et al. 2019) and regulates the formation of lateral shoots and floral meristems with ATHB-15 (Prigge et al. 2005; Chano et al. 2021). We also identified lka-miR-10-3p-166, targeting three homologues of HD-ZIP III genes HOX32, ATHB8, and ATHB-15, suggesting that the roles of HD-ZIP IIIs in L. kaempferi are similar to angiosperms' throughout vascular development. However, the xylem tissues of L. kaempferi contain only tracheids without vessels and fibers. We need to further learn how miR165/166-HD-ZIP III regulates xylem formation in gymnosperms.

\section{miRNA Regulation of Meristem by Integrating Light and Mobile Signal}

IRL4 is involved in developmental signaling and response to light stimulus in A. thaliana (Forsthoefel et al. 2005, 2013). In Larix, an orthologous IRL4 gene targeted by lka-miR-8-5p (Fig. 5), was also identified, suggesting that the lka-miR-8$5 \mathrm{p}-I R L 4$ pathway may play a critical role in light signaling during $L$. kaempferi meristem development. Interestingly, the expression pattern of lka-miR-8-5p is significantly negatively correlated with that of lka-miR-1-5p-156 (Fig. 5), indicating that they antagonistically operate together to regulate the development of L. kaempferi meristems.

CRN can perceive the mobile signal CLV3 (CLAVATA3) to modulate meristem maintenance and floral organ development (Müller et al. 2008). Notably the homologue of $C R N$ gene targeted by lka-miR-6-5p is also identified in the agerelated regulatory network of L. kaempferi stems (Fig. 5), implying that CRN might correspond to a signal from CLV, a highly conserved regulator of coordinated stem cell proliferation and differentiation (Somssich et al. 2016; Fletcher 2018).

To our knowledge, miR162 targets endoribonuclease dicer homolog 1 ( $D C L 1)$ to maintain the proper level of DCL1 in Arabidopsis (Rajagopalan et al. 2006). However, the types of predicted lka-miR-3-3p-162 targets are varied (Fig. 5), including retrovirus-related pol polyprotein from transposon TNT 1-94 (RRPPTTNT1-94), B3 domaincontaining protein (Os06g0194400), and pentatricopeptide repeat (PPR)-containing protein (At3g13150). To date, the function of retrovirus-related polyproteins in plants remains unknown. The plant-specific B3 domain-containing protein belongs to a large transcription factor superfamily, including the LAV (LEC2 [Leafy Cotyledon 2]/ABI3 [Abscisic Acid Insensitive 3]-VAL [VP1/ABI3-like]), RAV (Related to ABI3/VP1), ARF, and REM (reproductive meristem) families (Wang et al. 2012). They are all closely associated with mobile signal hormones and reproductive growth. PPR proteins are a large family of modular RNA-binding proteins and their PPR motifs are involved in RNA processing, splicing, editing, stability, and translation (Small and Peeters 2000; Schmitz-Linneweber and Small 2008; Manna 2015). Given that the expression lka-miR-3-3p-162 correlated with the expression of several other miRNAs and targeted multiple transcripts (Fig. 5), it appears to be a key node in the regulatory network as it has versatile functions.

PAP14 (Probable Plastid-Lipid-Associated Protein 14) directly regulated by DOF3.6/OBP3 (Dof zinc finger protein DOF3.6), can phosphorylate proteins to regulate gene expression and the mitotic cell cycle. OBP3 modulates phytochrome and cryptochrome signaling in response to light changes in A. thaliana (Ward et al. 2005). In the age-related miRNA regulatory network of Larix meristems, lka-miR12-5p targets the PAP14 gene (Fig. 5), indicating that the lka-miR-12-5p-PAP14 pathway might play an important role in light control of the activity of L. kaempferi meristems.

Cms1 ribosomal small subunit homolog (CMSS1) can bind to RNA and modify amino acids (Xie et al. 2021), thus suggesting it may take part in RNA or protein biosynthesis and modification. Although knowledge about CMSS1 is very limited, it is targeted by the age-related lka-miR-3-5p in Larix (Fig. 5), indicating that aging involves the change of protein biosynthesis mediated by this pathway.

\section{Conclusion}

The molecular mechanisms governing the activity and identity of meristems are complicated, integrating sRNAs, transcription factors, small peptides, enzymes, hormones, age-related signaling, and environmental cues. Herein, we identified three miRNAs whose expressions changed depending on L. Kaempferi tree age, and 17 showed coordinated expression patterns with three age-related miRNAs in current-year stems of L. kaempferi with different age. All miRNAs and their targets constituted a miRNA-mediated regulatory network underlying chronological development of meristems in L. kaempferi. Although there are many unknown components, the age-related miRNA regulatory network identified here contributes to a deeper understanding of meristem development in L. kaempferi, a perennial, gymnosperm, woody tree, which is different in many aspects 
from angiosperms. We also expect the future revisions of the age-related L. kaempferi miRNA regulatory network as more individuals of different ages, genotypes, and various growth conditions are surveyed, and more miRNAs and their targets are annotated, which will contribute to the development of functional genomics in the post-genomic era.

\section{Materials and Methods}

\section{Plant Materials}

L. kaempferi samples were collected in July 2011 in Dagujia seed orchard $\left(42^{\circ} 22^{\prime} \mathrm{N}, 124^{\circ} 51^{\prime} \mathrm{E}\right)$, in the Liaoning Province, Northeast China, as the same as those described previously (Li et al. 2014, 2017). To cover the major development phases of L. kaempferi, the current-year-defoliated uppermost main stems were harvested from three 2-, 5-, 10-, 25-, and 50-year-old L. kaempferi trees and from ten 1-year-old trees, and they all were grown from seeds in nursery garden of Dagujia seed orchard. The stems of trees at the same age were pooled, frozen in liquid nitrogen, and stored at $-80^{\circ} \mathrm{C}$ for RNA extraction.

\section{sRNA Library Construction and Sequencing}

Total RNAs was extracted from tree stems of the same age using TRIzol ${ }^{\circledR}$ Reagent according to the manufacturer's instructions (Invitrogen, Carlsbad, CA, USA). Genomic DNA was removed using DNase I RNase-free (TaKara). After total RNA integrity was assessed using an Agilent Technologies 2100 Bioanalyzer (Santa Clara, CA, USA), we isolated small RNAs (sRNA) (16 to $30 \mathrm{nt}$ long) from the total RNA using size fractionation in a 15\% TBE-urea polyacrylamide gel (Invitrogen). Those sRNAs were used to create RNA sequencing libraries using TruSeqTM Small RNA Sample Prep Kits (Illumina, USA) according to the manufacturer's instructions. The purified and validated cDNA constructs were then used for sequencing on an Illumina HiSeq 2000 platform. All sequencing reads were deposited in the NCBI SRA database with the accession number PRJNA234461.

\section{Identification and Annotation of $L$. kaempferi miRNAs}

Raw sequence reads were filtered using Cutadapt 1.8.1 (Martin 2011). During this procedure, all low-quality reads $(Q<20)$, adapter sequences from reads, and 5'-adapter contaminants were removed. Subsequently, sequences between 18 and $30 \mathrm{nt}$ from the filtered reads were extracted and subjected to further analysis. Briefly, the extracted sequences were analyzed by BLAST against the Rfam database (ftp.
sanger.ac.uk/pub/databases/Rfam) to annotate rRNA, tRNA, small nuclear RNA, and other non-coding RNA sequences. Then, the sRNA sequences were used to predict potential miRNAs using MIREAP (http://sourceforge.net/projects/ mireap/) to compare them with transcriptome sequences of L. kaempferi (Li et al. 2017). Only those sRNAs that satisfied the essential criteria described by Axtell and Meyers (2018) and Kozomara et al. (2019) were considered highconfidence miRNAs. The secondary structures of the putative miRNA precursors were then predicted on the Mfold web server (http://unafold.rna.albany.edu/?q=mfold/downl oad-mfold) (Zuker 2003) with default parameters.

To infer homology, we used BlastN to compare the set of 29 high-confidence miRNAs to the miRBase v22 database (http://www.mirbase.org/) and used ClustalX to compare their target sites to those of corresponding homologous miRNAs. If a miRNA sequence was homologous to known miRNAs in the miRBase and its target site was also homologous to those of corresponding known miRNAs, it was identified as a conserved miRNA and annotated by homology, or it was considered to be a novel miRNA.

\section{Expression Analysis of miRNAs}

Expression levels of the miRNAs were determined using normalized transcripts, and each miRNA expression was measured in reads per million reads. The normalized expression equals the actual miRNA count per total count of clean reads times 1,000,000.

\section{Analysis of Age Effects on miRNA Expression}

We estimated the effect of age on miRNA expression using linear-to-cubic models for each miRNA with base2, log-transformed age as predictor, and expression level as response. The best regression model was selected from all possible linear-to-cubic models using adjusted $\mathrm{R}^{2}$ and $\mathrm{F}$ tests. MiRNAs that had adjusted $R^{2}>0.8$ and $F$ test $P \leq 0.05$ were defined age-related miRNAs.

\section{Prediction of the miR390-TAS3-ARF Pathway}

We predicted miR390 targets using the psRNATarget web server (http://plantgrn.noble.org/psRNATarget/) (Dai et al. 2018) with the following default parameters: expectation is 3 and HSP size is the same as the miRNA length. Only the sequences with two miR390 complementary sites and at least one tasiARF were considered as TAS3 candidates (Axtell et al. 2006; Xia et al. 2017). Larix ARF homologous sequences were identified in the L. kaempferi transcriptome using TBlastN with $A$. thaliana ARF genes retrieved from PlantTFDB (planttfdb.cbi.pku.edu.cn) (Jin et al. 2017) as query sequences. We predicted tasiRNA-targeted $A R F$ 
genes from Larix ARF transcripts using the psRNATarget web server (http://plantgrn.noble.org/psRNATarget/) (Dai et al. 2018).

\section{Prediction and Annotation of the Target Genes of $L$. kaempferi miRNAs}

We predicted potential miRNA target genes from the assembled L. kaempferi mRNA transcriptome (Li et al. 2017) using the psRNATarget web server with default parameters. The target genes were annotated by searching homologous sequences using BlastX against the UniProtKB with an e value of $1 \mathrm{e}^{-5}$. We selected the top hits to the annotated transcripts and assigned the Gene Ontology (GO) terms (Supplementary Table S3).

\section{Construction of miRNA-Mediated Regulatory Network}

To investigate thoroughly miRNAs underlying meristem development chronologically, the coordinated miRNAs with age-related miRNA at different correlation levels were identified by the Pearson correlation coefficient (PCC) between the expression patterns of the age-related miRNAs and other miRNAs. MiRNAs with $\mid \mathrm{PCCl} \geq 0.8$ between their expression patterns were considered to be coordinated. The coordinated miRNAs were organized hierarchically by PCCs of their expression patterns. Age-related miRNAs were defined as the first rank of hierarchy, then miRNAs directly correlated with age-related miRNAs were defined the second rank of hierarchy, and so on. After that, miRNA targets and their annotations were added to establish the miRNA-mediated regulatory network. The statistical analyses were performed with the Statistical Product and Service Solutions program (SPSS Statistics 26, IBM Corp. New York, USA). Cytoscape (https://cytoscape.org/) (Shannon 2003) was used to create the regulatory network.

Supplementary Information The online version contains supplementary material available at https://doi.org/10.1007/s00344-021-10436-w.

Acknowledgements We would like to thank Hui Dong for proofreading references.

Author Contributions W-FL conceived the study, carried out RNA-seq, and revised the manuscript. L-WQ provided suggestions on the experimental design and analyses, and W-HY carried out the study and wrote the manuscript. All authors read and approved the final manuscript.

Funding This work was supported by the Fundamental Research Funds for the Central Non-profit Research Institution of CAF [CAFYBB2017SY006, RIF2014-07], the National Natural Science Foundation of China [31770714], and the National Transgenic Major Program [2018ZX08020-003]. The funders did not play any roles in the design of the study, collection, analysis and interpretation of the relevant data, and writing the manuscript.
Data Availability Raw sequence data are available in NCBI's Short Read Archive (SRA) with the accession number PRJNA234461.

Code Availability Not applicable.

\section{Declarations}

Conflict of interests The authors declare that they have no competing interests.

Ethics Approval and Consent to Participate Not applicable.

Consent for Publication Not applicable.

Open Access This article is licensed under a Creative Commons Attribution 4.0 International License, which permits use, sharing, adaptation, distribution and reproduction in any medium or format, as long as you give appropriate credit to the original author(s) and the source, provide a link to the Creative Commons licence, and indicate if changes were made. The images or other third party material in this article are included in the article's Creative Commons licence, unless indicated otherwise in a credit line to the material. If material is not included in the article's Creative Commons licence and your intended use is not permitted by statutory regulation or exceeds the permitted use, you will need to obtain permission directly from the copyright holder. To view a copy of this licence, visit http://creativecommons.org/licenses/by/4.0/.

\section{References}

Adrian J, Torti S, Turck F (2009) From decision to commitment: the molecular memory of flowering. Mol Plant 2(4):628-642

Allen E, Xie Z, Gustafson AM, Carrington JC (2005) microRNAdirected phasing during trans-acting siRNA biogenesis in plants. Cell 121(2):207-221

Alvarez Buylla ER, García Ponce B, Sánchez MDLP, Espinosa Soto C, García Gómez ML, Piñeyro Nelson A, Garay Arroyo A (2019) MADS-box genes underground becoming mainstream: plant root developmental mechanisms. New Phytol 223(3):1143-1158

Amasino R (2010) Seasonal and developmental timing of flowering. Plant J 61(6):1001-1013

Aung B, Gruber MY, Amyot L, Omari K, Bertrand A, Hannoufa A (2015) MicroRNA156 as a promising tool for alfalfa improvement. Plant Biotechnol J 13(6):779-790

Axtell MJ, Jan C, Rajagopalan R, Bartel DP (2006) A two-hit trigger for siRNA biogenesis in plants. Cell 127(3):565-577

Axtell MJ, Meyers BC (2018) Revisiting criteria for plant microRNA annotation in the era of big data. Plant Cell 30(2):272-284

Baima S, Possenti M, Matteucci A, Wisman E, Altamura MM, Ruberti I, Morelli G (2001) The Arabidopsis ATHB-8 HD-zip protein acts as a differentiation-promoting transcription factor of the vascular meristems. Plant Physiol 126(2):643-655

Bao W, O'Malley DM, Whetten R, Sederoff RR (1993) A laccase associated with lignification in loblolly pine xylem. Science 260(5108):672-674

Berthet S, Demont-Caulet N, Pollet B, Bidzinski P, Cézard L, Le Bris P, Borrega N, Hervé J, Blondet E, Balzergue S, Lapierre C, Jouanin L (2011) Disruption of LACCASE4 and 17 results in tissuespecific alterations to lignification of Arabidopsis thaliana stems. Plant Cell 23(3):1124-1137

Brunoni F, Ljung K, Bellini C (2019) Control of root meristem establishment in conifers. Physiol Plantarum 165(1):81-89 
Budak H, Bulut R, Kantar M, Alptekin B (2016) MicroRNA nomenclature and the need for a revised naming prescription. Brief Funct Genom 15(1):26

Bustamante M, Matus JT, Riechmann JL (2016) Genome-wide analyses for dissecting gene regulatory networks in the shoot apical meristem. J Exp Bot 67(6):1639-1648

Byrne ME (2006) Shoot meristem function and leaf polarity: the role of class III HD-ZIP genes. PLoS Genet 2(6):e89

Cabrera J, Barcala M, García A, Rio Machín A, Medina C, Jaubert Possamai S, Favery B, Maizel A, Ruiz Ferrer V, Fenoll C, Escobar C (2016) Differentially expressed small RNAs in Arabidopsis galls formed by Meloidogyne javanica: a functional role for miR390 and its TAS3-derived tasiRNAs. New Phytol 209(4):1625-1640

Carlsbecker A, Lee J, Roberts CJ, Dettmer J, Lehesranta S, Zhou J, Lindgren O, Moreno-Risueno MA, Vatén A, Thitamadee S, Campilho A, Sebastian J, Bowman JL, Helariutta Y, Benfey PN (2010) Cell signalling by microRNA165/6 directs gene dosedependent root cell fate. Nature 465(7296):316-321

Chano V, Sobrino Plata J, Collada C, Soto A (2021) Wood development regulators involved in apical growth in Pinus canariensis. Plant Biol 23(3):438-444

Chuck G, Meeley R, Irish E, Sakai H, Hake S (2007) The maize tasselseed 4 microRNA controls sex determination and meristem cell fate by targeting Tasselseed6/indeterminate spikelet1. Nat Genet 39(12):1517-1521

Côté CL, Boileau F, Roy V, Ouellet M, Levasseur C, Morency M, Cooke JE, Séguin A, MacKay JJ (2010) Gene family structure, expression and functional analysis of HD-Zip III genes in angiosperm and gymnosperm forest trees. BMC Plant Biol 10(1):273

Couzigou JM, Combier JP (2016) Plant microRNAs: key regulators of root architecture and biotic interactions. New Phytol 212(1):22-35

Dai X, Zhuang Z, Zhao PX (2018) psRNATarget: a plant small RNA target analysis server (2017 release). Nucleic Acids Res 46(W1):W49-W54

Desvignes T, Batzel P, Berezikov E, Eilbeck K, Eppig JT, McAndrews MS, Singer A, Postlethwait JH (2015) miRNA nomenclature: a view incorporating genetic origins, biosynthetic pathways, and sequence variants. Trends Genet 31(11):613-626

Donner TJ, Sherr I, Scarpella E (2009) Regulation of preprocambial cell state acquisition by auxin signaling in Arabidopsis leaves. Development 136(19):3235-3246

Fahlgren N, Montgomery TA, Howell MD, Allen E, Dvorak SK, Alexander AL, Carrington JC (2006) Regulation of AUXIN RESPONSE FACTOR3 by TAS3 ta-siRNA affects developmental timing and patterning in Arabidopsis. Curr Biol 16(9):939-944

Fletcher JC (2018) The CLV-WUS stem cell signaling pathway: a roadmap to crop yield optimization. Plants 7(4):87

Forsthoefel N, Klag K, Simeles B, Reiter R, Brougham L, Vernon D (2013) The Arabidopsis plant intracellular Ras-group LRR $(P I R L)$ family and the value of reverse genetic analysis for identifying genes that function in gametophyte development. Plants 2(3):507-520

Forsthoefel NR, Cutler K, Port MD, Yamamoto T, Vernon DM (2005) PIRLs: a novel class of plant intracellular leucine-rich repeat proteins. Plant Cell Physiol 46(6):913-922

Fouracre JP, Poethig RS (2019) Role for the shoot apical meristem in the specification of juvenile leaf identity in Arabidopsis. Proc Natl Acad Sci USA 116(20):10168-10177

Freudenberg K (1959) Biosynthesis and constitution of lignin. Nature 183(4669):1152-1155

Garcia D, Collier SA, Byrne ME, Martienssen RA (2006) Specification of leaf polarity in Arabidopsis via the trans-acting siRNA pathway. Curr Biol 16(9):933-938
Gatsuk LE, Smirnova OV, Vorontzova LI, Zaugolnova LB, Zhukova LA (1980) Age states of plants of various growth forms: a review. J Ecol 68(2):675

Gorham SR, Weiner AI, Yamadi M, Krogan NT (2018) HISTONE DEACETYLASE 19 and the flowering time gene FD maintain reproductive meristem identity in an age-dependent manner. $\mathrm{J}$ Exp Bot 69(20):4757-4771

Greenwood MS (1995) Juvenility and maturation in conifers: current concepts. Tree Physiol 15(7-8):433-438

Griffiths-Jones S, Hui JHL, Marco A, Ronshaugen M (2011) MicroRNA evolution by arm switching. EMBO Rep 12(2):172-177

Griffiths-Jones S, Russell JG, Stijn VD, Alex B, Enright AJ (2006) miRBase: microRNA sequences, targets and gene nomenclature. Nucleic Acids Res 34(90001):D140-D144

Hobecker KV, Reynoso MA, Bustos-Sanmamed P, Wen J, Mysore KS, Crespi M, Blanco FA, Zanetti ME (2017) The microRNA390/ TAS3 pathway mediates symbiotic nodulation and lateral root growth. Plant Physiol 174(4):2469-2486

Huijser P, Schmid M (2011) The control of developmental phase transitions in plants. Development 138(19):4117-4129

Hunter C, Willmann MR, Wu G, Yoshikawa M, de la Luz Gutierrézava M, Poethig SR (2006) Trans-acting siRNA-mediated repression of ETTIN and ARF4 regulates heteroblasty in Arabidopsis. Development 133(15):2973-2981

Jin J, Tian F, Yang D, Meng Y, Kong L, Luo J, Gao G (2017) PlantTFDB 4.0: toward a central hub for transcription factors and regulatory interactions in plants. Nucleic Acids Res 45(D1):D1040-D1045

Johnson DM, McCulloh KA, Woodruff DR, Meinzer FC (2012) Hydraulic safety margins and embolism reversal in stems and leaves: Why are conifers and angiosperms so different? Plant Sci 195:48-53

Jouannet V, Brackmann K, Greb T (2015) (Pro)cambium formation and proliferation: two sides of the same coin? Curr Opin Plant Biol 23:54-60

Kozomara A, Birgaoanu M, Griffiths-Jones S (2019) miRBase: from microRNA sequences to function. Nucleic Acids Res 47(D1):D155-D162

Kozomara A, Griffiths-Jones S (2013) miRBase: annotating high confidence microRNAs using deep sequencing data. Nucleic Acids Res 42(D1):D68-D73

Kozomara A, Griffiths-Jones S (2010) miRBase: integrating microRNA annotation and deep-sequencing data. Nucleic Acids Res 39:D152-D157

Lai M, Sun X, Chen D, Xie Y, Zhang S (2014) Age-related trends in genetic parameters for Larix kaempferi and their implications for early selection. BMC Genet 15(Suppl 1):S10

Lauter N, Kampani A, Carlson S, Goebel M, Moose SP (2005) microRNA172 down-regulates glossy15 to promote vegetative phase change in maize. Proc Natl Acad Sci USA 102(26):9412-9417

Lenhard M, Laux T (1999) Shoot meristem formation and maintenance. Curr Opin Plant Biol 2(1):44-50

Li W, Han S, Qi L, Zhang S (2014) Transcriptome resources and genome-wide marker development for Japanese larch (Larix kaempferi). Front Agric Sci Eng 1(1):77

Li W, Yang W, Zhang S, Han S, Qi L (2017) Transcriptome analysis provides insights into wood formation during larch tree aging. Tree Genet Genomes 13(1):19

Lu S, Li Q, Wei H, Chang MJ, Tunlaya-Anukit S, Kim H, Liu J, Song J, Sun YH, Yuan L, Yeh TF, Peszlen I, Ralph J, Sederoff RR, Chiang VL (2013) Ptr-miR397a is a negative regulator of laccase genes affecting lignin content in Populus trichocarpa. Proc Natl Acad Sci USA 110(26):10848-10853

Manna S (2015) An overview of pentatricopeptide repeat proteins and their applications. Biochimie 113:93-99 
Marco A, MacPherson JI, Ronshaugen M, Griffiths-Jones S (2012) MicroRNAs from the same precursor have different targeting properties. Silence 3(1):8

Marin E, Jouannet V, Herz A, Lokerse AS, Weijers D, Vaucheret H, Nussaume L, Crespi MD, Maizel A (2010) miR390, Arabidopsis TAS3 tasiRNAs, and their AUXIN RESPONSE FACTOR targets define an autoregulatory network quantitatively regulating lateral root growth. Plant Cell 22(4):1104-1117

Martin M (2011) Cutadapt removes adapter sequences from highthroughput sequencing reads. Embnet J 17(1):10-12

Miura K, Ikeda M, Matsubara A, Song X, Ito M, Asano K, Matsuoka M, Kitano H, Ashikari M (2010) OsSPL14 promotes panicle branching and higher grain productivity in rice. Nat Genet 42(6):545-549

Miyashima S, Koi S, Hashimoto T, Nakajima K (2011) Non-cellautonomous microRNA165 acts in a dose-dependent manner to regulate multiple differentiation status in the Arabidopsis root. Development 138(11):2303-2313

Mouradov A, Cremer F, Coupland G (2002) Control of flowering time. Plant Cell 14(suppl 1):S111-S130

Müller R, Bleckmann A, Simon R (2008) The receptor kinase CORYNE of Arabidopsis transmits the stem cell-limiting signal CLAVATA3 independently of CLAVATA1. Plant Cell 20(4):934-946

Muraro D, Mellor N, Pound MP, Help H, Lucas M, Chopard J, Byrne HM, Godin C, Hodgman TC, King JR, Pridmore TP, Helariutta Y, Bennett MJ, Bishopp A (2014) Integration of hormonal signaling networks and mobile microRNAs is required for vascular patterning in Arabidopsis roots. Proc Natl Acad Sci USA 111(2):857-862

Nieminen K, Blomster T, Helariutta Y, Mähönen AP (2015) Vascular cambium development. Arabidopsis Book 13:e177

Pajoro A, Madrigal P, Muiño JM, Matus J, Jin J, Mecchia MA, Debernardi JM, Palatnik JF, Balazadeh S, Arif M, Maoiléidigh DS, Wellmer F, Krajewski P, Riechmann J, Angenent GC, Kaufmann K (2014) Dynamics of chromatin accessibility and gene regulation by MADS-domain transcription factors in flower development. Genome Biol 15(3):R41

Poethig RS (1990) Phase change and the regulation of shoot morphogenesis in plants. Science 250(4983):923-930

Poethig RS (2013) Vegetative phase change and shoot maturation in plants. Curr Top Dev Biol 105(7):125-152

Poethig RS (2009) Small RNAs and developmental timing in plants. Curr Opin Genet Dev 19(4):374-378

Prigge MJ, Otsuga D, Alonso JM, Ecker JR, Drews GN, Clark SE (2005) Class III homeodomain-leucine zipper gene family members have overlapping, antagonistic, and distinct roles in Arabidopsis development. Plant Cell 17(1):61-76

Qiu Z, Li X, Zhao Y, Zhang M, Wan Y, Cao D, Lu S, Lin J (2015) Genome-wide analysis reveals dynamic changes in expression of microRNAs during vascular cambium development in Chinese fir, Cunninghamia lanceolata. J Exp Bot 66(11):3041-3054

Rajagopalan R, Vaucheret H, Trejo J, Bartel DP (2006) A diverse and evolutionarily fluid set of microRNAs in Arabidopsis thaliana. Genes Dev 20(24):3407-3425

Ramachandran P, Carlsbecker A, Etchells JP (2016) Class III HDZIPs govern vascular cell fate: an HD view on patterning and differentiation. J Exp Bot 68(1):55-69

Riese M, Zobell O, Saedler H, Huijser P (2007) SBP-domain transcription factors as possible effectors of cryptochrome-mediated blue light signalling in the moss Physcomitrella patens. Planta 227(2):505-515

Rubio-Somoza I, Weigel D (2011) MicroRNA networks and developmental plasticity in plants. Trends Plant Sci 16(5):258-264
Schmitz-Linneweber C, Small I (2008) Pentatricopeptide repeat proteins: a socket set for organelle gene expression. Trends Plant Sci 13(12):663-670

Schoof H, Lenhard M, Haecker A, Mayer KFX, Jürgens G, Laux T (2000) The stem cell population of Arabidopsis shoot meristems is maintained by a regulatory loop between the CLAVATA and WUSCHEL Genes. Cell 100(6):635-644

Schwarz S, Grande AV, Bujdoso N, Saedler H, Huijser P (2008) The microRNA regulated SBP-box genes SPL9 and SPL15 control shoot maturation in Arabidopsis. Plant Mol Biol 67(1-2):183-195

Shannon P (2003) Cytoscape: a software environment for integrated models of biomolecular interaction networks. Genome Res 13(11):2498-2504

Small ID, Peeters N (2000) The PPR motif-a TPR-related motif prevalent in plant organellar proteins. Trends Biochem Sci 25(2):46-47

Smetana O, Mäkilä R, Lyu M, Amiryousefi A, Sánchez Rodríguez F, Wu M, Solé-Gil A, Leal Gavarrón M, Siligato R, Miyashima S, Roszak P, Blomster T, Reed JW, Broholm S, Mähönen AP (2019) High levels of auxin signalling define the stem-cell organizer of the vascular cambium. Nature 565(7740):485-489

Somssich M, Je BI, Simon R, Jackson D (2016) CLAVATAWUSCHEL signaling in the shoot meristem. Development 143(18):3238-3248

Srikanth A, Schmid M (2011) Regulation of flowering time: all roads lead to Rome. Cell Mol Life Sci 68(12):2013-2037

Telfer A, Bollman KM, Poethig RS (1997) Phase change and the regulation of trichome distribution in Arabidopsis thaliana. Development 124(3):645-654

Teotia S, Tang G (2015) To bloom or not to bloom: role of microRNAs in plant flowering. Mol Plant 8(3):359-377

Tripathi RK, Bregitzer P, Singh J (2018) Genome-wide analysis of the $\mathrm{SPL} / \mathrm{miR} 156$ module and its interaction with the AP2/miR172 unit in barley. Sci Rep 8(1):1-13

Turchi L, Baima S, Morelli G, Ruberti I (2015) Interplay of HD-Zip II and III transcription factors in auxin-regulated plant development. J Exp Bot 66(16):5043-5053

Wang C, Zhang S, Yu Y, Luo Y, Liu Q, Ju C, Zhang Y, Qu L, Lucas WJ, Wang X, Chen Y (2014) MiR397b regulates both lignin content and seed number in Arabidopsis via modulating a laccase involved in lignin biosynthesis. Plant Biotechnol J 12(8):1132-1142

Wang J, Park MY, Wang L, Koo Y, Chen X, Weigel D, Poethig RS (2011) MiRNA control of vegetative phase change in trees. PLoS Genet 7(2):e1002012

Wang J, Schwab R, Czech B, Mica E, Weigel D (2008) Dual effects of miR156-targeted SPL Genes and CYP78A5/KLUH on plastochron length and organ size in Arabidopsis thaliana. Plant Cell 20(5):1231-1243

Wang Y, Deng D, Zhang R, Wang S, Bian Y, Yin Z (2012) Systematic analysis of plant-specific B3 domain-containing proteins based on the genome resources of 11 sequenced species. Mol Biol Rep 39(5):6267-6282

Ward JM, Cufr CA, Denzel MA, Neff MM (2005) The Dof transcription Factor OBP3 modulates phytochrome and cryptochrome signaling in Arabidopsis. Plant Cell 17(2):475-485

Willmann MR, Poethig RS (2005) Time to grow up: the temporal role of smallRNAs in plants. Curr Opin Plant Biol 8(5):548-552

Wu G, Park MY, Conway SR, Wang J, Weigel D, Poethig RS (2009) The sequential action of miR156 and miR172 regulates developmental timing in Arabidopsis. Cell 138(4):750-759

Wu G, Poethig RS (2006) Temporal regulation of shoot development in Arabidopsis thaliana by miR156 and its target SPL3. Development 133(18):3539-3547 
Xia R, Xu J, Meyers BC (2017) The emergence, evolution, and diversification of the miR390-TAS3-ARF pathway in land plants. Plant Cell 29(6):1232-1247

Xie Y, Luo X, He H, Pan T, He Y (2021) Identification of an individualized RNA binding protein-based prognostic signature for diffuse large B-cell lymphoma. Cancer Med 10(8):2703-2713

Xu M, Hu T, Zhao J, Park M, Earley KW, Wu G, Yang L, Poethig RS (2016) Developmental functions of miR156-regulated SQUAMOSA PROMOTER BINDING PROTEIN-LIKE (SPL) Genes in Arabidopsis thaliana. PLoS Genet 12(8):e1006263

Yamaguchi A, Abe M (2012) Regulation of reproductive development by non-coding RNA in Arabidopsis: to flower or not to flower. J Plant Res 125(6):693-704

Yang C, Xu Z, Song J, Conner K, Vizcay Barrena G, Wilson ZA (2007) Arabidopsis MYB26/MALE STERILE35 regulates secondary thickening in the endothecium and is essential for anther dehiscence. Plant Cell 19(2):534-548

Ye Z, Zhong R (2015) Molecular control of wood formation in trees. J Exp Bot 66(14):4119-4131

Yi Chou E, Schuetz M, Hoffmann N, Watanabe Y, Sibout R, Samuels AL (2018) Distribution, mobility, and anchoring of lignin-related oxidative enzymes in Arabidopsis secondary cell walls. J Exp Bot 69(8):1849-1859

Yu S, Lian H, Wang J (2015) Plant developmental transitions: the role of microRNAs and sugars. Curr Opin Plant Biol 27:1-7

Zhang J, Zhang S, Han S, Wu T, Li X, Li W, Qi L (2012) Genomewide identification of microRNAs in larch and stage-specific modulation of 11 conserved microRNAs and their targets during somatic embryogenesis. Planta 236(2):647-657

Zhang T, Lian H, Tang H, Dolezal K, Zhou C, Yu S, Chen J, Chen Q, Liu H, Ljung K, Wang J (2015) An intrinsic microRNA timer regulates progressive decline in shoot regenerative capacity in plants. Plant Cell 27(2):349-360

Zhao Q, Nakashima J, Chen F, Yin Y, Fu C, Yun J, Shao H, Wang X, Wang Z, Dixon RA (2013) LACCASE is necessary and nonredundant with PEROXIDASE for lignin polymerization during vascular development in Arabidopsis. Plant Cell 25(10):3976-3987

Zhao Y, Lin S, Qiu Z, Cao D, Wen J, Deng X, Wang X, Lin J, Li $X$ (2015) MicroRNA857 is involved in the regulation of secondary growth of vascular tissues in Arabidopsis. Plant Physiol 169:2539-2552

Zhu Q, Helliwell CA (2011) Regulation of flowering time and floral patterning by miR172. J Exp Bot 62(2):487-495

Zotz G, Wilhelm K, Becker A (2011) Heteroblasty-A Review. Bot Rev 77(2):109-151

Zuker M (2003) Mfold web server for nucleic acid folding and hybridization prediction. Nucleic Acids Res 31(13):3406-3415

Publisher's Note Springer Nature remains neutral with regard to jurisdictional claims in published maps and institutional affiliations. 